\title{
miR-505-3p is a repressor of puberty onset in female mice
}

\author{
Yuxun Zhou'1, Li Tong1', Maochun Wang'1, Xueying Chang', Sijia Wang', Kai Li1 and Junhua Xiao'1,2 \\ 1The College of Chemistry, Chemical Engineering \& Biotechnology, Donghua University, Songjiang, Shanghai, China \\ ${ }^{2}$ Human Phenome Institute, Fudan University, Shanghai, China
}

Correspondence should be addressed to J Xiao: xiaojunhua@dhu.edu.cn

\begin{abstract}
Puberty onset is a complex trait regulated by multiple genetic and environmental factors. In this study, we narrowed a puberty-related QTL region down to a $1.7 \mathrm{Mb}$ region on chromosome $\mathrm{X}$ in female mice and inferred miR-505-3p as the functional gene. We conducted ectopic expression of miR-505-3p in the hypothalamus of prepubertal female mice through lentivirus-mediated orthotopic injection. The impact of miR-505-3p on female puberty was evaluated by the measurement of pubertal/reproduction events and histological analysis. The results showed that female mice with overexpression of miR-505-3p in the hypothalamus manifested later puberty onset timing both in vaginal opening and ovary maturation, followed by weaker fertility lying in the longer interval time between mating and delivery, higher abortion rate and smaller litter size. We also constructed miR-505-3p-knockout mice by CRISPR/Cas9 technology. miR-505-3p-knockout female mice showed earlier vaginal opening timing, higher serum gonadotrophin and higher expression of puberty-related gene in the hypothalamus than their WT littermates. Srsf1 proved to be the target gene of miR-505-3p that played the major role in this process. The results of RNA immunoprecipitation sequencing showed that SRSF1 (or SF2), the protein product of Srsf1 gene, mainly bound to ribosome protein (RP) mRNAs in GT1-7 cells. The collective evidence implied that miR-505-3p/SRSF1/RP could play a role in the sexual maturation regulation of mammals.
\end{abstract}

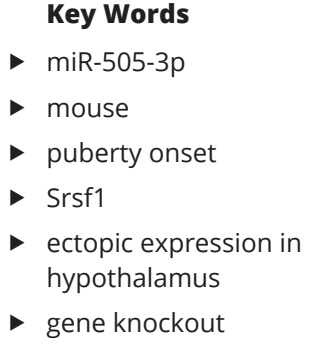

Journal of Endocrinology (2019) 240, 379-392

\section{Introduction}

Puberty onset is an essential and complicated physiology process that relies on the activation of the hypothalamic-pituitary-gonadal axis. The pulsatile secretion of GnRH hormones from specialized neurons in the hypothalamus trigger a gonadal hormonesecreting cascade that results in the maturation of sexual behaviors and signals the transition from nonreproductive juvenile into a fertile adult (Sisk \& Foster 2004, Holder \& Blaustein 2014). The dysregulation of pubertal development is involved in health risks in later life, including type 2 diabetes, cardiovascular disease, breast cancer and other health disorders (Day et al. 2015).

During the last decade, novel central neuroendocrine pathways in the control of puberty have been revealed. In 2017, genome-wide association studies including the genotype data of up to $\sim 370,000$ women identified 389 independent signals for age at menarche; 250 genes were implicated via coding variation or associated expression (Day et al. 2017). The maternal imprinted gene MKRN3 was the first gene identified by whole-exome sequencing of pedigree samples with an inhibitory effect on GnRH 
secretion, related to central precocious puberty (Abreu et al. 2013). System biology strategies revealed that at least three gene networks might contribute to puberty onset (Lomniczi et al. 2013). Moreover, a number of distinguished accomplishments have been made in revealing the epigenetic mechanisms of pubertal and reproductive regulation, among which microRNAs proved to play an essential role, together with DNA methylation and long noncoding RNA (lncRNAs). MicroRNAs are endogenous, small noncoding RNAs ( 22nt in length) which silence gene expression at a post-transcriptional level by targeting the $3^{\prime}$ untranslated region (UTRs) of mRNAs. They are involved in various biological processes, including cellular proliferation and body development (Bartel 2004), as well as tumorigenesis. Okabe et al. indicated that the knockout of miR-200b and miR-429 could induce reduced fertility in female mice (Hasuwa et al. 2013). Zhu et al. showed that the variation in the Lin28/let7 pathway changed the body size and puberty timing in mice (Zhu et al. 2010). Furthermore, miR-132, miR-9 and miR-145 were also involved in pubertal timing modulation owing to their potential regulatory role of c-myc and Lin28 (Sachdeva \& Mo 2010, Sangiao-Alvarellos et al. 2013). In 2016, Messina et al. reported a microRNA switch that controlled the rise of hypothalamic GnRH production before puberty in mice (Messina et al. 2016). These results suggested the existence of a multilayered and interconnected array of miRNAs and their target genes which control puberty timing (Lomniczi et al. 2015).

In our previous studies, we isolated a QTL region (quantitative trait locus) on chromosome $\mathrm{X}$ affecting the vaginal opening in female mice (Zhu et al. 2008). In this study, we narrowed this QTL region down to a $1.7 \mathrm{Mb}$ region by constructing eight interval-specific congenic strains (ISCSs) between C57/BL6 (B6) and C3H/He (C3H) mice. Among the genes in this region, miR-505-3p was assumed to be the potential candidate due to the variation in its flanking sequence and gene expression differences between $\mathrm{C} 3 \mathrm{H}$ and $\mathrm{B} 6$ mice, as well as its functional annotation.

miR-505-3p usually serves as a biomarker of various diseases including primary biliary cirrhosis, Parkinson's disease and inflammatory bowel disease (Khoo et al. 2012, Pekow \& Kwon 2012, Ninomiya et al. 2013). Zucchi et al. discovered the downregulation of miR-505-3p in newborn rat brain in response to prenatal stress (Zucchi et al. 2013). Moreover, miR-505-3p was proved to induce apoptosis in MCF7-ADR cells and functions as a tumor-suppressive miRNA (Yamamoto et al. 2011). The first experimentally validated target of miR-505-3p was the alternative splicing

(c) 2019 Society for Endocrinology Published by Bioscientifica Ltd. Printed in Great Britain factor/splicing factor2 (ASF/SF2 or SRSF1) (Verduci et al. 2010), which was a regulator of the mTOR (mammalian target of rapamycin) pathway (Karni et al. 2008); this activated mTOR signaling could accelerate vaginal opening in female rats (Roa et al. 2009). Such indirect evidence tempted us to clarify the authentic relationship between miR-505-3p and mammalian puberty onset regulation.

In this study, we attempted to verify the role that miR-505-3p played in the puberty onset regulation of female mice and to find the target gene by which miR-505-3p performs its function. We induced overexpression of miR-505-3p in the hypothalamus of prepubertal female mice through lentivirus-mediated orthotopic injection. We also constructed miR-505-3pknockout mice (miR-505-3p -/-) by CRISPR/Cas9 technology. The impact of miR-505-3p on female puberty was then evaluated. The results show that female mice with ectopic expression of miR-505-3p in the hypothalamus manifested later puberty onset timing, compromised fertility, higher abortion rates and smaller litter sizes. mir-505-knockout female mice showed slightly earlier vaginal opening and shorter interval time between mating and delivery. Srsf 1 proved to be the target gene of miR-505-3p that played the major role in this process. The results of RNA immunoprecipitation sequencing (RIP-Seq) showed that SRSF1, the protein of the Srsf1 gene, mainly bound to ribosome protein (RP) mRNAs in GT1-7 cells.

\section{Materials and methods}

\section{Fine mapping of the puberty-related QTL on chromosome $X$ in mice}

In our previous work, a significant puberty-related ChrX QTL of $2.5 \mathrm{~cm}$ was found by genome scanning, in a panel of ten modified interval-specific congenic strains (mISCSs) between C57/BL6 and C3H/He mice (Zhu et al. 2008). In this study, the mice of the strain carrying the QTL region were backcrossed with $\mathrm{C} 3 \mathrm{H}$ mice. The resulting male F2 mice holding at least one recombination in the interval of interest were chosen and then backcrossed with female $\mathrm{C} 3 \mathrm{H}$ to obtain $\mathrm{N} 2$ generation. The female N2 continued to mate with male $\mathrm{C} 3 \mathrm{H}$ to generate $\mathrm{N} 3$ generation. N3 male mice holding only one recombination at the target interval were selected and continued to backcross with female $\mathrm{C} 3 \mathrm{H}$ to generate an $\mathrm{N} 4$ generation. N4 mice siblings were crossed until N7 generation. Finally, the age at VO of all female mice of N7 progenies was then recorded. All modified ISCSs were verified by genotyping for the genetic 
markers on chromosome X. All animal procedures were approved by the Animal Ethics Committee of Donghua University, and all experiments were conducted in strict accordance with the National Institutes of Health Guide for the Use of Laboratory Animals.

\section{SNP database querying between $\mathrm{C} 3 \mathrm{H}$ and $\mathrm{B} 6$ mice and validation}

The SNPs between $\mathrm{C} 3 \mathrm{H}$ and $\mathrm{B} 6$ mice in the QTL region (rs13483770 rs299055848) on chromosome $\mathrm{X}$ were queried with the Sanger Database Mouse Genomes Project (http://www.sanger.ac.uk/science/data/mouse-genomesproject). The genes in the QTL region were PCR amplified and the DNA sequences were verified by the Sanger sequencing method.

\section{Quantitative RT-PCR detection for the genes in the QTL region and puberty-related genes in GT1-7 cells}

Total RNA from the hypothalamus or $10^{6}$ cells were isolated using TRIzol reagent (Invitrogen) in line with the manufacturer's protocol. One microgram of total RNA was reverse-transcribed with oligo-dT (for mRNA detection) or microRNA-specific primer (for microRNA detection) using a RevertAid First-Strand cDNA Synthesis Kit (ThermoFisher). Real-time PCR was performed using SuperReal PreMix Plus (TIANGEN, Beijing, China) on a 7500 Real-time PCR System (Applied Biosystems) and normalized to $A c t b$ (for mRNA) or miR-16 (for microRNA). All reactions were run in triplicate and included no template control for each gene. All PCR primers are listed in Supplementary Table 1 (see section on supplementary data given at the end of this article).

\section{Generation of hypothalamic miR-505 overexpressing mice}

C57/BL6 (B6) inbred mice were purchased from Shanghai SLAC Laboratory Animals Co. Ltd (Shanghai, China) and were divided into three groups randomly: the lentivirusinjected group $(n=12)$, the saline-injected group $(n=10)$ and the non-injected group $(n=11)$. The miR-505-3p carrying lentivirus delivery was performed on female mice at postnatal day $12-15$ weighing $5.2-5.6 \mathrm{~g}$. After $1 \%$ sodium pentobarbital anesthesia, mice were fixed on stereotaxic apparatus (Stoelting, USA). According to Paxions et al. (He et al. 2009), the hypothalamic stereotaxic coordinates were carried out relative to the bregma (anteroposterior $(\mathrm{AP})=-1.53 \mathrm{~mm}$ and lateral $(\mathrm{L})= \pm 0.24 \mathrm{~mm})$ and to the skull (dorsoventral $(\mathrm{DV})=-5.3 \mathrm{~mm})$. The injection of lentiviral preparation $(2.83 \mathrm{E}+08 \mathrm{IU} / \mathrm{mL}, 900 \mathrm{~nL}$ per sample) was at the rate of $30 \mu \mathrm{L} / \mathrm{min}$. Saline was also injected to the female mice to be used as controls in the same conditions. After injection, the mice were kept at $37^{\circ} \mathrm{C}$ until they recovered from anesthesia. Afterwards, the mice were placed back with their mothers.

\section{Cryostat section and in situ hybridizations}

Mice were killed after investigating the phenotypes of puberty onset timing and fertility. Mice were under 1\% sodium pentobarbital anesthesia and perfused by $0.9 \%$ saline. When the color of liver and lung become pale, saline was replaced by $4 \%$ paraformaldehyde to fix the tissues. Then, the brains or ovaries were taken out and kept in paraformaldehyde solution at $4^{\circ} \mathrm{C}$ overnight. The fixed brains and ovaries were dehydrated by glucose solution and cut into sections using Cryotome (Thermo). The thickness of brain and ovary sections was 15 and $20 \mu \mathrm{m}$, respectively. The sections were attached to slides which were pretreated with potassium dichromate and embedded in polylysine. Slides were stored at $-80^{\circ} \mathrm{C}$ until objected to FISH, and hematoxylin and eosin (HE) staining, respectively.

Brain sections were taken out from $-80^{\circ} \mathrm{C}$ and dried at room temperaturefor at least $10 \mathrm{~min}$. The sections werefixed by $4 \%$ paraformaldehyde and pretreated with TritonX-100 and Proteinase $\mathrm{K}$ to improve the tissue permeability. After pre-hybridization, sections were hybridized with diluted digoxigenin (DIG)-labeled LNA probes for miR-505-3p, (5'-AGAAAACCAGCAAGTGTTGACG-3') at $55^{\circ} \mathrm{C}$ overnight. Then, the sections were washed and incubated with horseradish peroxidase (HRP)-conjugated anti-DIG antibodies (Abcam) at $4^{\circ} \mathrm{C}$ overnight. The fluorescent signals were amplified using a TSA Cyanine 5 System (PerkinElmer) and detected by an inverted phase contrast fluorescence microscope (Olympus).

Ovarian sections were taken out from $-80^{\circ} \mathrm{C}$ and dried for at least $10 \mathrm{~min}$. Then the sections were dehydrated with ethanol and stained with HE. The morphology of ovaries was detected by light microscope (Olympus).

\section{Measurement of pubertal events and fertility analysis}

The animals were housed under the specific pathogenfree standard conditions with a 12-h light/darkness cycle and adequate water and food. Injected and control female pups were caged with their mothers and weighed every 
2 days. After weaning at postnatal day 21, the mice were examined daily for vaginal opening. They were mated with fertile male mice at the age of 8 weeks at the ratio of two to one. Female mice with drastic body weight gain were assumed to be pregnant and were separated from male mice into a single cage. The interval time between mating and delivery was recorded. Female mice that failed to be pregnant for more than 1 month or had two successive abortions were regarded as sterile. The rate of sterility in female mice and the death rate of newborns were calculated. Mice with and without saline injection were used as control.

\section{Generation of miR-505-knockout mice}

The miR-505-knockout mice were generated with CRISPR/Cas9 technology by the Animal Facility of the Institute of Neuroscience, Chinese Academy of Sciences. Female B6 mice were superovulated using pregnant mare serum gonadotropin and were injected with human chorionic gonadotropin after $48 \mathrm{~h}$. The superovulated female mice were mated with B6 stud males, and the fertilized eggs were collected from their oviducts after $36 \mathrm{~h}$. Two sgRNAs were designed to guide Cas9 targeting the pre-miR-505 locus (Supplementary Fig. 1). A mixture of transcribed Cas9 mRNA and sgRNA was microinjected into zygotes of B6 mice. The injected zygotes were transferred into the uterus of pseudopregnant female mice immediately after injection. The pregnant mice were housed in standard cages on a $12 \mathrm{~h}$ light/darkness cycle with ad libitum access to food and water until delivery.

The pups were taken by tail clips and their DNAs were extracted for sequencing. Pups with large deletions in the pre-mir-505 region were reserved as founders. The generated male and female founders were mated with WT B6 mice at the age of 40 days. The heterozygote F1 mice were self-crossed to generate double-knockout (DKO), single-knockout (SKO) and WT mice for further puberty event study. The resulting female mice were genotyped by PCR detection with the primers, forward: 5'-AAACCAGCAAGTGTTGACGC, reverse: 5'-CCCTGTTTGTCACTTGCAGA. The lengths of the PCR products were $120 \mathrm{bp}$ for WT, 103, 120 and 97, 120bp for heterozygous and 97 and $103 \mathrm{bp}$ for homozygous knockout mice.

\section{Hormone detection}

Mouse blood serum was extracted by orbital blood sampling. The detection of serum luteinizing hormone
(LH) or follicle-stimulating hormone (FSH) was performed using a Mouse LH ELISA KIT or a Mouse FSH ELISA KIT (Elabscience, Wuhan, China) according to the manufacturer's procedures, respectively. The standard curve was plotted by CurveExpert 1.4 software, which was also used to calculate the concentration of LH and FSH by referring to the standard curve.

\section{Construction of the GT1-7 cell line with miR-505-3p stable overexpression and Srsf1-knockdown}

GT1-7 cells are immortalized cell lines derived from mouse hypothalamic neurosecretory neurons, which provide an ideal model system for study of the regulation of reproduction, because of their similarity to GnRH neurons in terms of the synthesis, processing and pulsatile secretion of GnRH (gonadotropin-releasing hormone) (Mellon et al. 1990). The GT1-7 cells used in this study were kindly provided by Professor Xiaoying Li of Shanghai Clinical Center for Endocrine and Metabolic Diseases, Shanghai Jiaotong University (as suggested by Dr Pamela Mellon at University of California, San Diego). The doublestrand DNA sequence of miR-505-3p was cloned into the pLenti6.3/V5-DEST lentiviral expression vector (Invitrogen).

The target sequence of shRNA for Srsf1 (5'-GCCCAGAAGTCCAAGTTAT-3') and nonspecific shRNA (5'-TTCTCCGAACGTGTCACGT-3') were synthesized and cloned into the PLKD-CMV-R\&PR-U6shRNA lentiviral expression vector. The resulting vectors were packaged into virions by Obio Technology Co. Ltd (Shanghai, China). The virions were used to infect GT1-7 cells. Cells were seeded 100,000 cells per well in 24-well plates and cultured in DMEM medium with 10\% fetal bovine serum (FBS, Gibco). After 4 days of transfection, cells were selected under antibiotics according to the vector's resistances for 14 days. After 10 days of growth without antibiotics, the surviving cells were harvested for further investigation. GT1-7 cells with miR-505-3p overexpression were named pGT1-7 cells.

We used a GeneChip Mouse Transcriptome Assay 1.0 (Affymetrix) to get the transcriptome data of pGT1-7, and GT1-7 as the control, in triplicate for each sample. Differentially expressed genes were used to perform KEGG analysis based on the Kyoto Encyclopedia of Genes and Genomes database.

\section{RNA immunoprecipitation sequencing (RIP-Seq)}

We performed RNA immunological precipitation (RIP) assays followed by high-throughput sequencing in 
SRSF1 pulldown of GT1-7 cell, IgG pulldown and total RNA as the control. Briefly, cells were cross-linked with $1 \%$ formaldehyde for $10 \mathrm{~min}$, and cross-linking was terminated with glycine. After harvesting, the cells were resuspended in lysing buffer $(150 \mathrm{mM} \mathrm{KCl}, 25 \mathrm{mM}$ Tris (pH 7.5), 5 mM EDTA, 1\% NP-40, 0.5 mM DTT , 1 X PIC, $100 \mathrm{U} / \mathrm{mL}$ RiboLock) and sonicated five times at $30 \mathrm{~s}$ on and $30 \mathrm{~s}$ off.

After cell lysis, $10 \%$ of the sample removed for input was stored at $-80^{\circ} \mathrm{C}$ until it was required for performing RNA purification. The input sample was used to calculate the RIP yields and evaluate the quality of the RNA. RNAbinding SRSF1-specific antibody or negative control IgG was added to the supernatant of the cell lysates and incubated with rotation at $4^{\circ} \mathrm{C}$ overnight. Afterward, protein $A+G$ agarose beads were added to each IP sample and incubated with rotation at $4^{\circ} \mathrm{C}$ for $2 \mathrm{~h}$, and then the antibody bound beads were collected by centrifugation at $950 \boldsymbol{g}$ for $10 \mathrm{~min}$ and washed with lysing buffer to remove the unbound material. RNAs bound to RNA-binding protein on the agarose beads were purified with TRIzol, and sequence analysis was done by next-generation sequencing.

\section{Results}

\section{miR-505-3p was identified as a functional candidate gene in the QTL region of chromosome $X$}

To further narrow down the QTL region that was identified previously, eight ISCSs with intervals within this region of B6 chromosome $\mathrm{X}$ were substituted into $\mathrm{C} 3 \mathrm{H}$ background in the N7 generation, the number of female mice in each ISCS was between 15 and 25. Nonparametric tests showed that strain \#1-3, 7 and 8 showed significantly different VO age from the parental strain $\mathrm{C} 3 \mathrm{H}$, while strain \#4-6 did not. Based on the QTL information and allele distribution among those strains, we narrowed the QTL region to about $1.7 \mathrm{Mb}$ between rs13483770 and rs299055848 (Fig. 1A and Supplementary Table 1).

There are 19 genes in the QTL region of chromosome $\mathrm{X}$, including seven pseudogenes, four ncRNAs, seven protein-coding genes and one microRNA gene. To screen for the candidate gene(s), we referred to the Sanger database to search for DNA sequence variations between $\mathrm{C} 3 \mathrm{H}$ and $\mathrm{B} 6$ mice in this region. Data showed that there were no SNPs, short indels or structural variants lying in the coding region, $5^{\prime}$ or $3^{\prime}$ UTR of these genes except for mir-505, as sensible variations of five consecutive SNPs

(C) 2019 Society for Endocrinology Published by Bioscientifica Ltd. Printed in Great Britain existed near the $5^{\prime}$ upstream region of the mir-505 gene (Supplementary Table 3). We performed DNA sequencing for the regions of interest in the 19 genes, and the results showed no exception compared with the public data. We compared the mRNA expression levels of the seven protein-coding genes in the HPG axis between three B6 and three $\mathrm{C} 3 \mathrm{H}$ female mice. Six of them were expressed except for the gene of Gm7073, but there were hardly significant differences in the amount of accumulation between the two strains, especially in the hypothalamus or pituitary (Fig. 1B). On the other hand, miR-505-3p was expressed more highly in the hypothalamus of B6 compared to $\mathrm{C} 3 \mathrm{H}$ (Fig. 1C) at postnatal day 15 and lower in the pituitary and ovary at postnatal day 45 .

We investigated the temporal and spatial expression pattern of miR-505-3p in three B6 female mice and found that miR-505-3p was most abundant in the hypothalamus of the four tested tissues (Fig. 1D); it reached the peak value of expression at neonatal period (PND5) and decreased gradually afterward (Fig. 1E), which implied its inhibiting role in the sexual maturation process. The integrated evidence suggested that miR-505-3p deserved further investigation as a functional candidate gene.

In pGT1-7 cells with stable overexpression of miR-505-3p, the expression level of miR-505-3p increased by 1500 times that of GT1-7 cells (Supplementary Fig. 1). We compared the expression profiling between pGT1-7 and GT1-7 (transfected with pLenti6.3-nc lentivirus) using a DNA microarray and found that some important puberty-related genes, including Kiss1 and GnRH, decreased in pGT1-7 cells. These results were confirmed by qRT-PCR assay (Fig. 1F), implying that miR-505-3p may participate in puberty onset regulation through the inhibition of puberty-related genes.

\section{Ectopic expression of miR-505-3p in the hypothalamus influences puberty onset timing and fertility of female mice}

Before the phenotype observation, we investigated the time course of miR-505-3p ectopic expression in the hypothalamus after orthotopic injection. We made lentivirus-mediated orthotopic injections in the hypothalamus of C57BL/6 (B6) female mice at postnatal day 15 and detected the miR-505-3p abundance at the 5th, 10th, 20th and 40th day after injection, in three mice for each time point. In the window of 5 to 40 days post injection, the hypothalamic miR-505-3p overexpression maintained a high level, reaching a peak at 10 days after injection (Chang et al. 2015). 
A
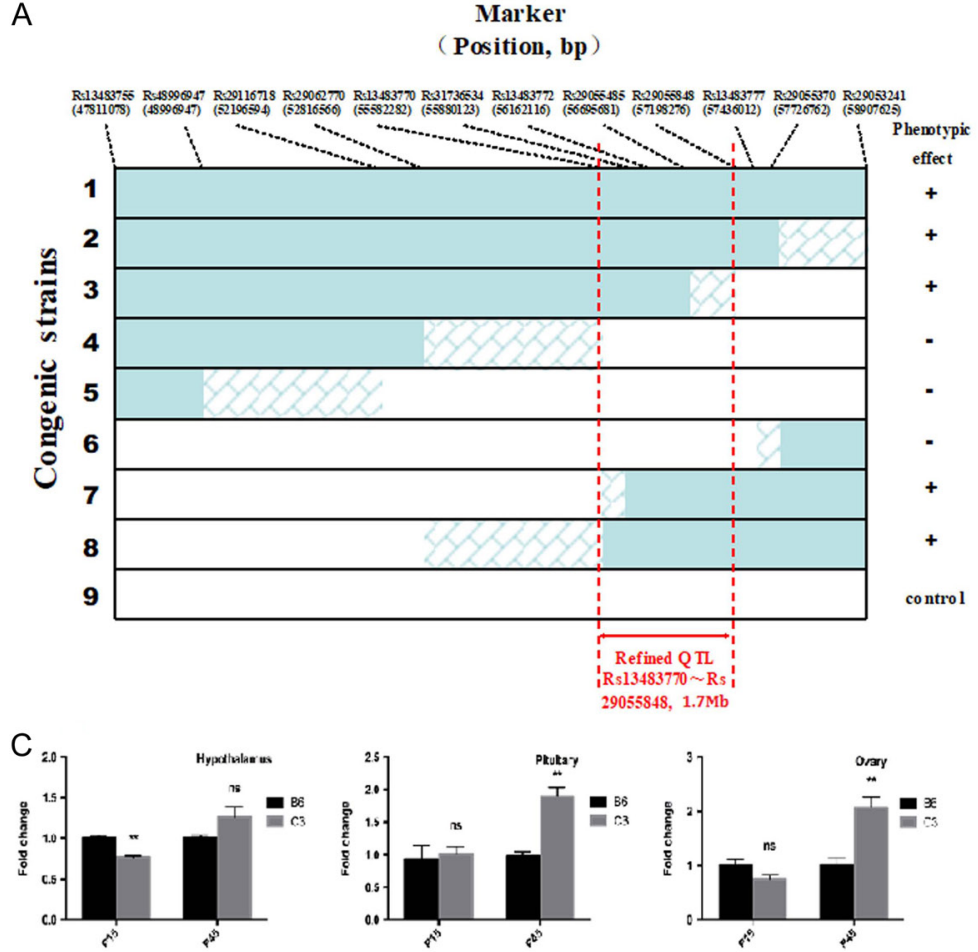

D

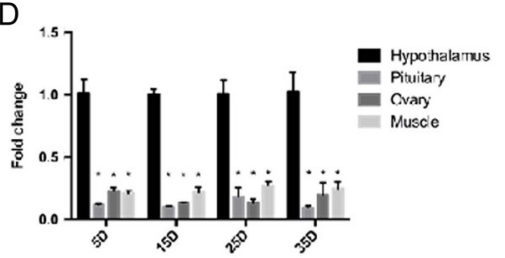

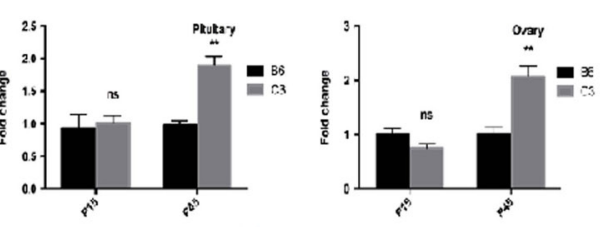

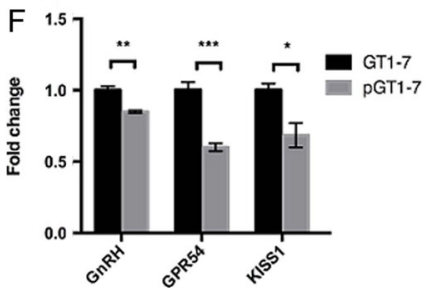

B

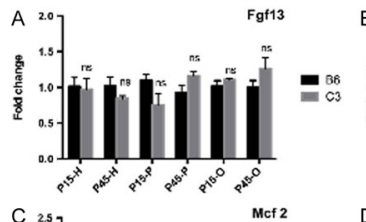

$\mathrm{C} 2.5$
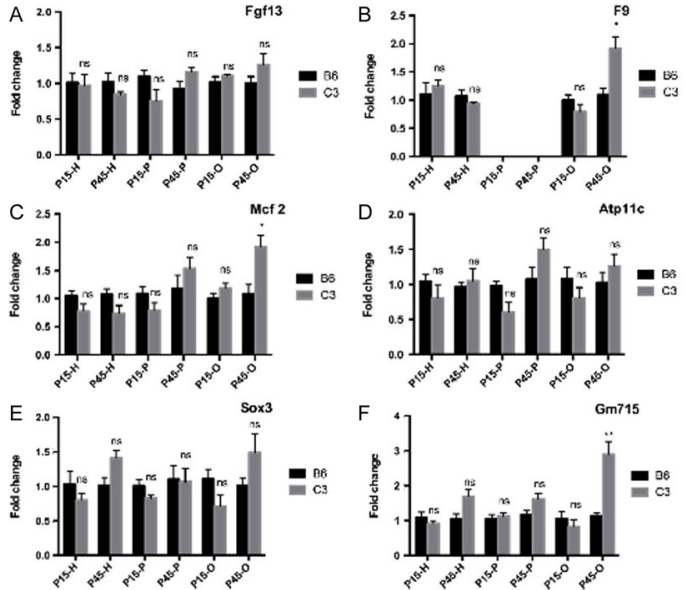

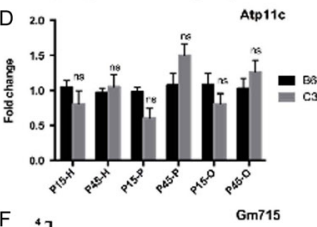

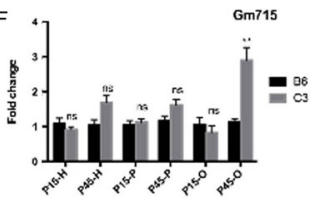

E
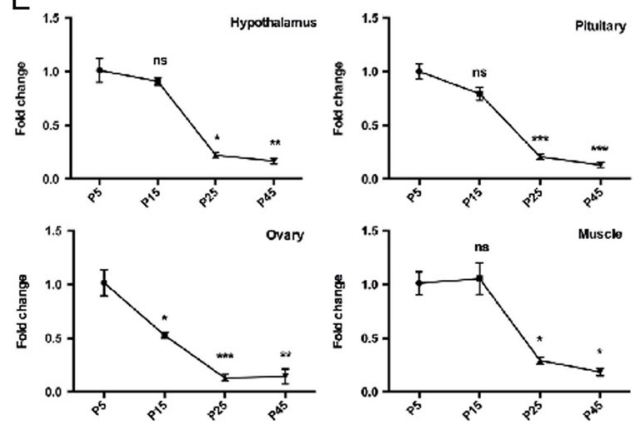

Figure 1

The evidence of miR-505-3p being a candidate gene in the puberty onset-related QTL region on chromosome X. (A) Schematic representation of the ISCSs and control strains. The genotype on chromosome $X$ for each of the eight congenic strains is represented by the horizontal bars. Green portions indicate a known homozygous B6 segment, blank portions represent a known homozygous C3H segment, and hatched regions depict an area where a crossover between $\mathrm{C} 3 \mathrm{H}$ and $\mathrm{B} 6$ occurs. The dotted lines indicate the boundary of the refined QTL region. (B) The expression situation of six protein-coding genes in the QTL region in HPG axis in B6 and C3H strains. H, hypothalamus; O, ovary; P, pituitary. (C) The expression difference of miR-505-3p in HPG axis between B6 and C3H mice. (D) The spatial-specific expression of miR-505-3p in different time point of B6 mice. (E) The temporal-specific expression of miR-505-3p in different tissues of B6 mice. (F) The expression level of puberty-related genes in GT1-7 and pGT1-7cells. Bars are means and vertical bars represent SEM $(* P<0.05, * * P<0.01, * \star * P<0.001)$.

The mice at each time point were also investigated for their ovary development. The HE-stained ovarian sections at various time points showed a delay in the formation of the preovulatory follicles and corpus luteums (CLs) in miR-505-3p-LV-treated (abbreviated as LV-treated) female mice, which provided an explanation for the later birth of newborn offspring in LV-treated mice; the reduced number of newborn offspring could be attributed to the deficiency or reduced number of preovulatory follicles (Fig. 2). At 5 days after injection, both the untreated and the LV-injected mouse did not attain puberty and had no preovulatory follicles or CL (Fig. 2A and B). At 20 days after injection (PND 35), the untreated mouse had ovulated, and had one CL, two preovulatory follicles and a number of preovulatory follicles, while the LV-injected mouse had one preovulatory follicle but no CL (Fig. 2C and D); at 30 and 40 days after injection (PND 45 and PND 55), both the untreated and LV-injected mice had CLs, preovulatory follicles and follicles at various developmental stages in their ovaries, but the former more CLs and preovulatory follicles than the latter (Fig. 2E, F, G and H).

In the following experiments, the LV-treated mice were weighted once every other day after injection, and the female mice showed significant growth retardation compared with the sham-injected mice (Fig. 3A). 


\begin{tabular}{l|l|l|r|r|}
\hline Journal of & Y Zhou et al. & miR-505-3p and puberty onset & $\mathbf{2 4 0 : 3}$ & $\mathbf{3 8 5}$ \\
Endocrinology & & &
\end{tabular}

$5 d$

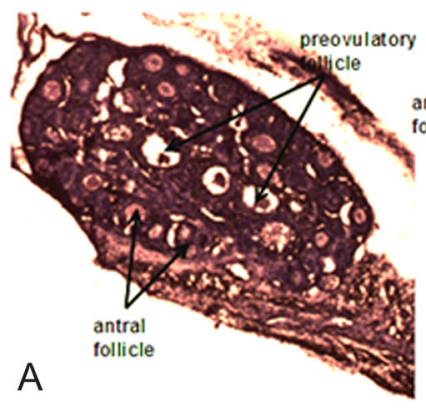

Control

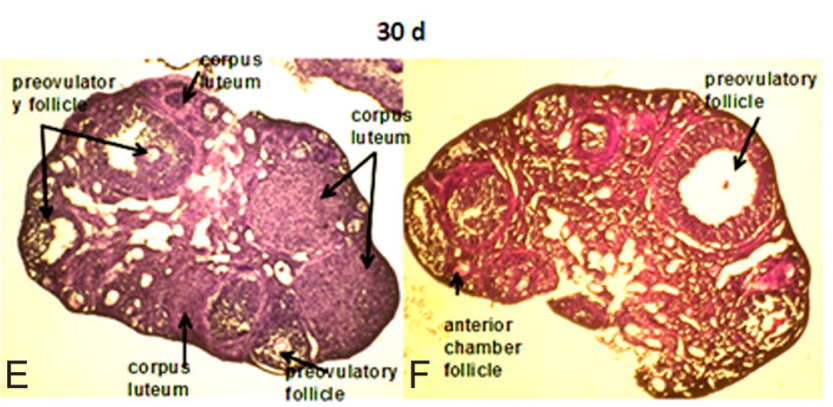

control

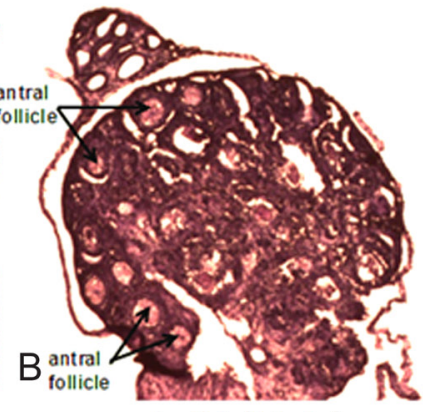

Lentiviral injected
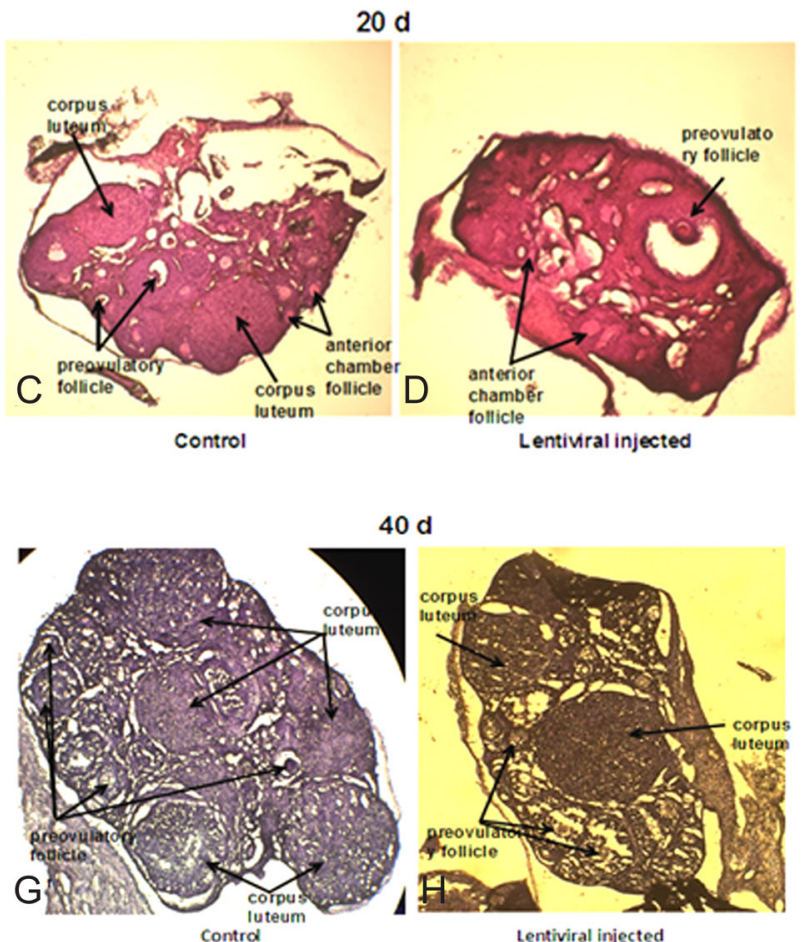

$40 \mathrm{~d}$

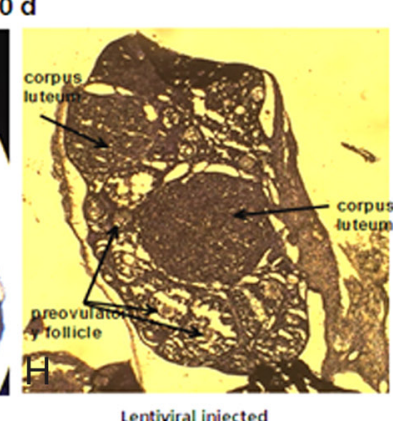

Figure 2

The HE-stained ovarian sections at various time points. Arrows in the graph point to different kinds of follicles before ovulation and $\mathrm{CL}$ after ovulation. (A and B) 5 days after injection, untreated, LV-treated, respectively. (C and D) 20 days after injection, untreated, LV-treated, respectively. (E and F) 30 days after injection, untreated, LV-treated, respectively. (G and H) 40 days after injection, untreated, LV-treated, respectively.

The vaginal opening in sham-injected mice was 2 days earlier than in LV-treated mice $(P<0.01)$ (Fig. 3B).

After sexual maturation (postnatal 8 weeks), the female mice were mated with WT experienced male mice to evaluate the long-term impact of hypothalamic miR-505-3p overexpression on reproduction. The LV-treated female mice needed more time to procreate and had smaller newborn litters compared with
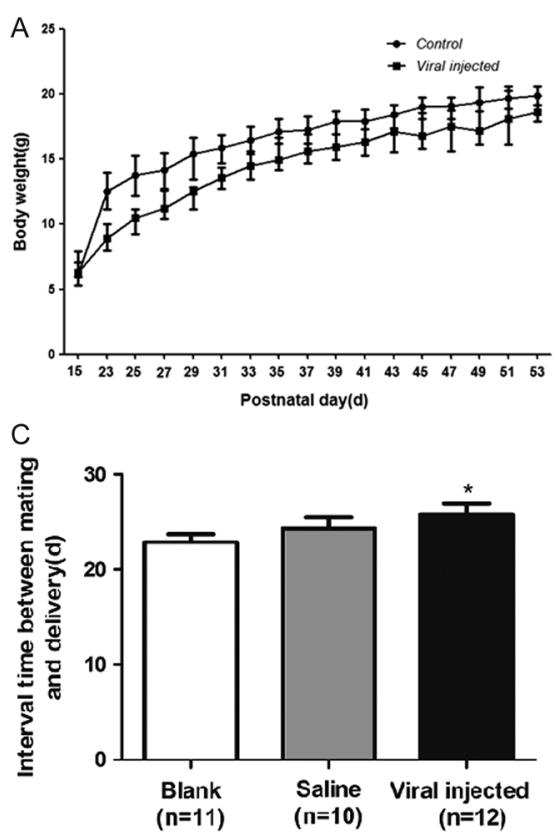

B

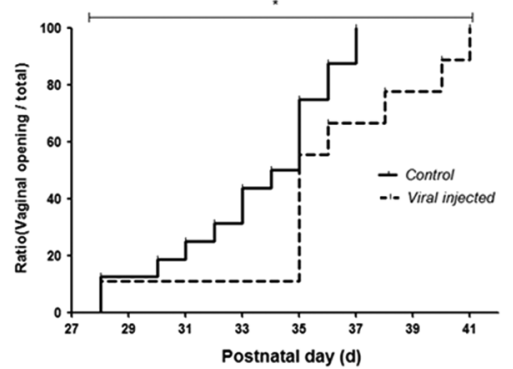

D

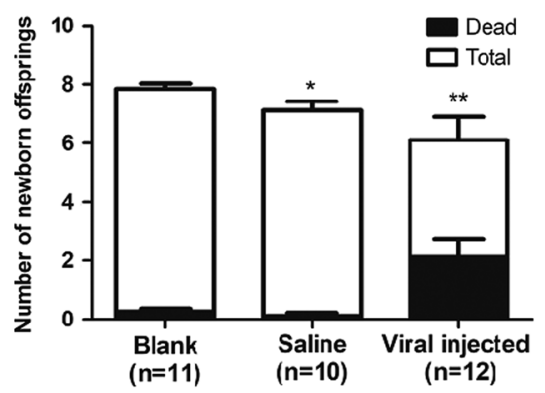

Figure 3

The influence of miR-505-3p ectopic expression in the hypothalamus on the body weight, $\mathrm{VO}$ timing and fertility of the tested mice. (A) The growth curve of the mice; (B) the VO time of the tested mice; (C) the interval time between paring with male mice and delivery

(LV-treated $=25.83 \pm 1.144$ days, saline-

treated $=24.33 \pm 1.247$ days,

untreated $=22.92 \pm 0.8307, * P<0.05)$; (D) the death rate of offspring before weaning of the tested mice (newborn offspring:

LV-treated $=6.100 \pm 0.794$, saline-

treated $=7.111 \pm 0.309$, untreated $=7.949 \pm 0.179$;

dead offspring: LV-treated $=2.111 \pm 0.626$,

saline-treated $=0.111 \pm 0.111$,

untreated $=0.256 \pm 0.108 .{ }^{*} P<0.05, * * P<0.01$ ). 
the control mice, and the death rate of offspring before weaning increased in LV-treated mice as well (Fig. 3C and D).

Moreover, we compared the pup status of mice between the three groups in more detail: each female mouse was observed for at least three litters. Pups that lived for less than $48 \mathrm{~h}$ after birth were defined as dead. We found that all three groups had one or two dead pups per litter, but $8 \%$ of all LV-injected mice had three dead pups per litter, significantly higher than the other two groups. In the LV-injected group, at least four dead pups appeared in $8 \%$ of litters, and no pups survived in $20 \%$ of litters. The rate of abortion in LV-treated groups was $20 \%, 2.5$-fold higher than the two control groups. A female mouse with two successive abortions was defined as infertile. About $8 \%$ of LV-treated mice were infertile in contrast with the control groups, in which no infertile mice were found (Fig. 4A). The FISH (fluorescence in situ hybridization) results of the brain sections showed a stronger miR-505-3p fluorescent signal near the third ventricle in the miR-505-3p-injected mice, compared with the control mice (Fig. 4B).

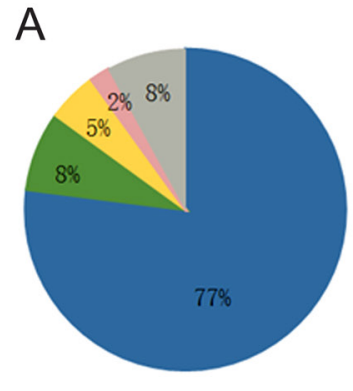

Blank

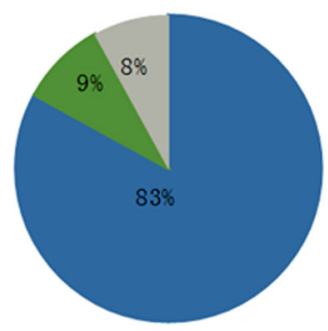

Saline
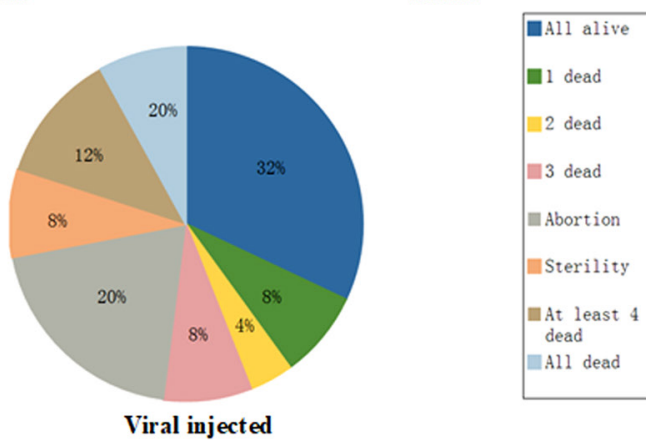

\section{miR-505-3p-knockout mice showed an earlier onset of puberty and abnormal reproductive phenotypes}

With the help of CRISPR/Cas9 technology, we obtained 41 living offspring, and 16 of them carried mutations in the mir-505 cDNA region on their genome, which we detected by DNA sequencing. Two pups with the largest deletion ( $-17 \mathrm{bp}$ and $-23 \mathrm{bp}$, respectively) adjacent to the $5^{\prime}$ end of miR-505 (Supplementary Fig. 2) and in the coding region of mature miR-505-5p were kept as founders to generate DKO miR-505-3p (-/-), SKO miR-505-3p (+/-) and WT mice for puberty-onset trait investigation by backcrossing to B6 mice. In DKO mice $(n=10)$, the expression level of miR-505-3p could hardly be measured, while in SKO mice $(n=12)$, the expression level of miR-505-3p decreased by approximately half compared with the WT mice $(n=7)$ (Supplementary Fig. 3). In female knockout mice, we observed an increased growth rate and a larger body weight at the same time but lower body weight at VO than WT mice (Fig. 5A and Table 1), 3.57 and 3.87 days earlier in vaginal opening than the SKO and DKO mice (Fig. 5B

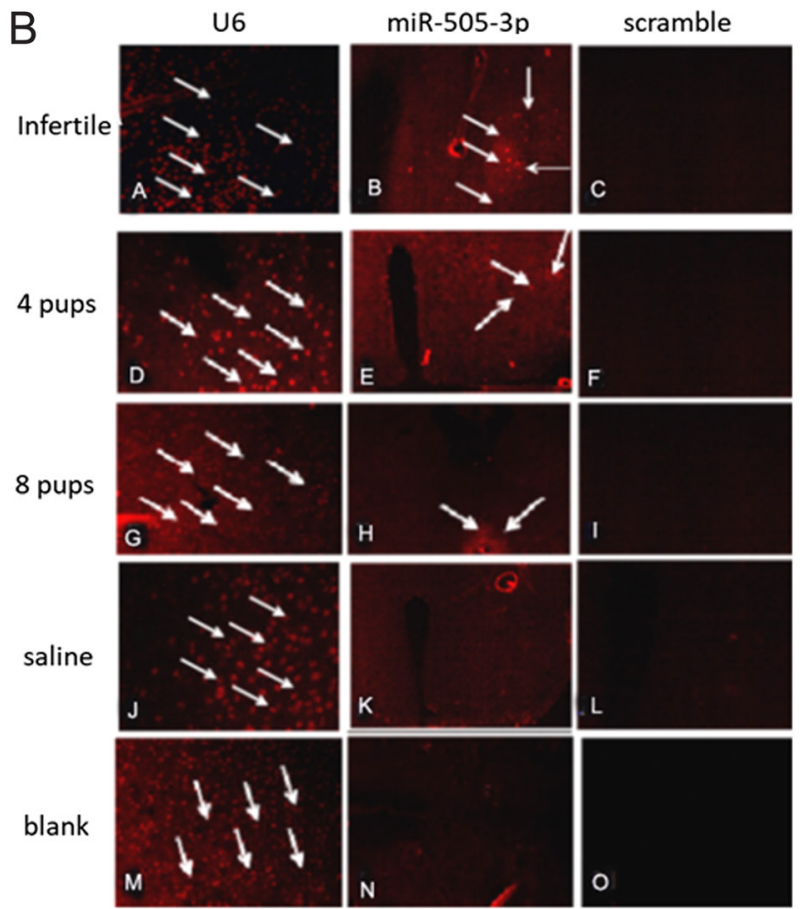

\section{Figure 4}

Fertility analysis of the miR-505-3p-overexpressed mice and in situ hybridization of their brain section. (A) Pie chart shows the percentage of female mice which had different number of dead pups per litter and the rate of abortion and infertility among the three groups; (B) Images of coronal sections showing the fluorescence signals of hypothalamic miR-505-3p detected by in situ hybridization among one sterile, one with reduced fertility, one normal, saline-treated and untreated mice using U6, miR-505-3p and scrambled LNA probes, respectively. The white arrows indicate the location of injection with most intensive florescence signals. 
and Table 1), respectively. At PND 45, the mass of the reproductive system was larger in knockout mice (Fig. 5C).

We then analyzed serum levels of the pituitary gonadotropins $\mathrm{LH}$ and $\mathrm{FSH}$, and the results showed a remarkable increase in female-knockout mice (Fig. 5D). Moreover, the size of the litter was larger in knockout mice than WT, and heterozygous-knockout mice showed more dystocia in female mice and more dead offspring at $48 \mathrm{~h}$ (Table 2). The ovarian sections of miR-505-3p-knockout mice showed more CLs (Fig. 5E). Srsf1, Kiss 1 and Gnrh in the hypothalamus of miR-505-3p-knockout mice and WT mice at different postnatal days were also detected, and the results showed knockout mice had higher expression levels (Fig. 6).

\section{Srsf1 proved to be a miR-505-3p target gene in the GT1-7 cell line}

We performed Gene Ontology analysis on the gene expression profiling data from the microarray detection between pGT1-7 and GT1-7 cells. Overall, 1490 genes were upregulated and 604 genes were downregulated in
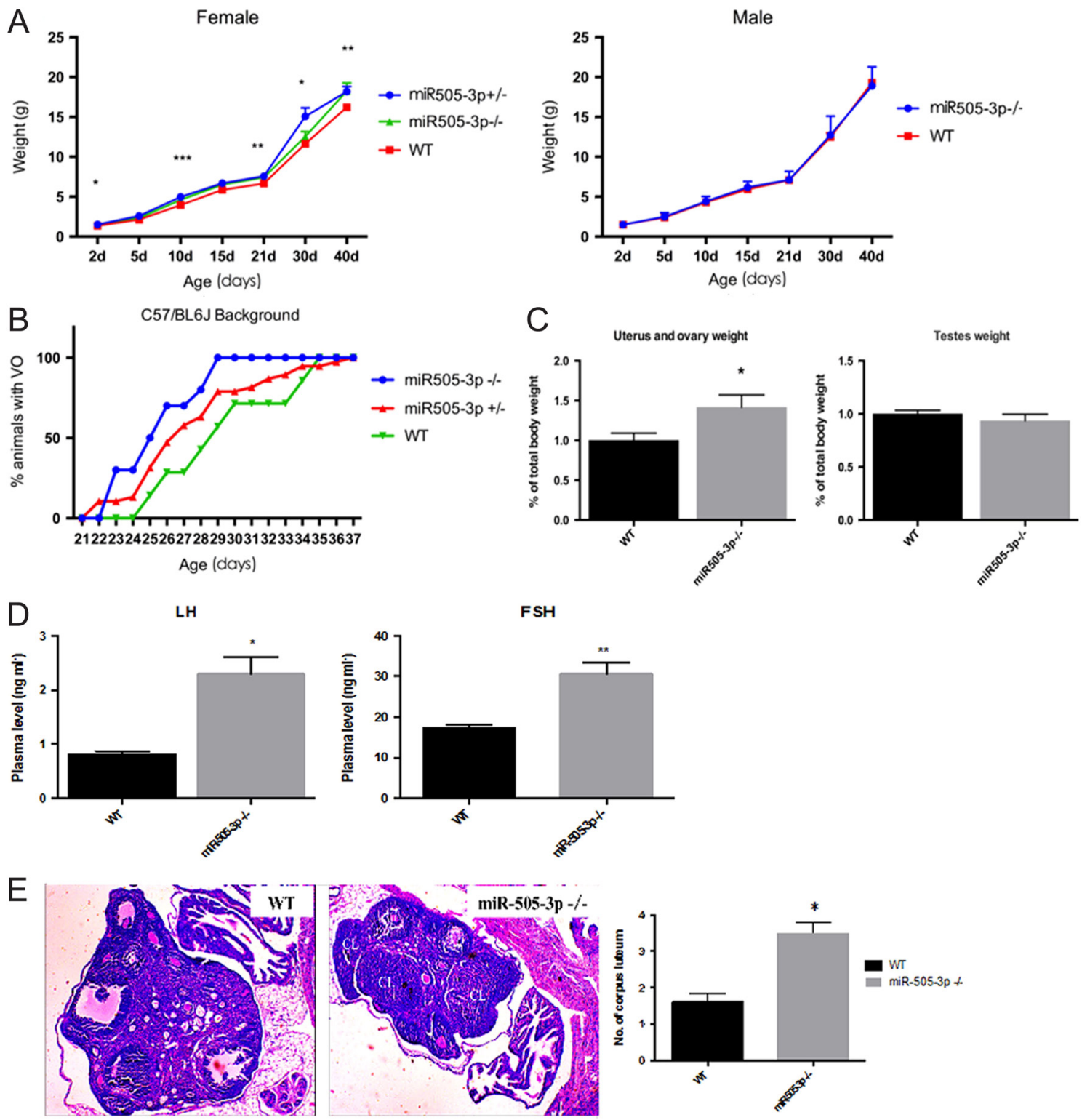

\section{Figure 5}

The phenotype of miR-505-3p-knockout mice. (A) The growth curve of the DKO, SKO and WT mice; (B) the percentage of female mice attaining VO at different time point; (C) the mass of reproductive system at PND45; (D) the serum LH and FSH of the DKO and WT mice; and (E) HE-stained ovarian sections of the tested mice. $(* P<0.05, * * P<0.01)$. 
Table 1 Mean age and body weight at time of $\mathrm{VO}$ in $\mathrm{KO}$ mice.

\begin{tabular}{lc}
\hline Strain & Mean age at vo (days)a \\
WT & $29.57(1.429)$ \\
SKO & $26.00(1.115)$ \\
DKO & $25.70(0.746)$ \\
\hline
\end{tabular}

\begin{tabular}{c}
\hline Number \\
\hline 7 \\
12 \\
10 \\
\hline
\end{tabular}

\begin{tabular}{c}
\hline P value $^{\mathbf{b}}$ \\
\hline 0.0667 \\
0.0197 \\
\hline
\end{tabular}

\begin{tabular}{c}
\hline Body weight at Vo $(\mathrm{g}) \mathbf{c}$ \\
\hline $11.39(0.809)$ \\
$10.34(0.700)$ \\
$9.810(0.432)$ \\
\hline
\end{tabular}

\begin{tabular}{l}
\hline P valued $^{-}$ \\
\hline 0.14 \\
0.043 \\
\hline
\end{tabular}

${ }^{a}$ Age at VO: mean (S.E.M.). ${ }^{b}$ Age at VO compared with WT. cMean (S.E.M.). dBody weight compared with WT.

the pGT1-7 cells. Among these genes, we screened for the miR-505-3p target genes using the TargetScan website. Four predicted genes, including Cd97, Hmbg1, Cadm1 and Srsf1 with a high expression level in GT1-7 cells were assumed to be the candidate targets of miR-505-3p. Dual luciferase reporter assays indicated that the other three genes except for Cadm1 could be the target genes of miR-505-3p (Supplementary Fig. 4A and B). Integrated with their functional annotation, Srsf 1 was selected preferentially for further investigation. Given that SRSF1 was proved to be a regulator of mTOR signaling, we analyzed the phosphorylated status of S6K, the downstream effector of the mTOR signaling pathway, in pGT1-7 cells at first, but the amount of phosphorylated S6K was not significantly different between GT1-7 and pGT1-7 cells (Supplementary Fig. 4C), which implied that miR-505-3p bypassed mTOR signaling to affect puberty onset in mice.

There was less accumulation of SRSF1 protein in pGT1-7 cells compared to GT1-7 cells (Fig. 7A). Knocking down Srsf1 expression in GT1-7 by shRNA inhibited not only the mRNA expression of Srsf1, but also the Kiss1 and Gnrh genes simultaneously. When the expression of Srsf1 was rescued in pGT1-7 cells by transfecting a plasmid carrying a Srsf1 expression cassette, the mRNA level of Kiss1 and Gnrh increased together with the elevated level of Srsf1 mRNA (Fig. 7B). These results indicate that miR-505-3p may inhibit the expression of puberty-related genes through Srsf1.

\section{RIP-seq results showed SRSF1 mainly bound to RP mRNAs}

We compared the RNA-seq data of the SRSF1 pull-down sample with two controls (one control was RNA pulled down by nonspecific IgG, the other was total RNA of
GT1-7 cells) respectively. The genes were first sorted according to the fold changes between the case and control samples. The top ten genes with the largest fold change in the two comparisons are listed in Table 3 and ranked by their abundance in the SRSF1 pull-down sample. The two results are highly overlapped: seven of the ten genes are shared, and five of them are ribosomerelated mRNAs (Table 3).

We performed KEGG analysis on the transcriptome data to compare differentially expressed genes in pGT1-7 and GT1-7 cells. The results showed that ribosome and ribosome biogenesis in the eukaryote pathway were both affected in the pGT1-7 cell line (Supplementary Figure 5).

\section{Discussion}

Genetic strategies, such as positional cloning and association study, can be powerful tools to reveal the functional genes underlying complex traits (Zhu et al. 2008, Sanford et al. 2008, Verduci et al. 2010, KuiriHänninen et al. 2014, Prevot 2015). We took advantage of mouse models to make ISCS between $\mathrm{C} 3 \mathrm{H} / \mathrm{He}$ and C57/BL6 mice to finemap the QTL regions related to puberty onset and then reveal the candidate gene by sequence variation, expression differentiation and functional connection. To our knowledge, miR-505-3p is the first microRNA to be found by positional cloning as a puberty regulator in female mice.

Considerable progress has been made to decipher the molecular foundation of pubertal timing (Topaloglu et al. 2008, Xu et al. 2011, Uenoyama et al. 2014). Some studies have revealed the potential epigenetic regulatory role of miRNAs and IncRNAs in female puberty onset and reproduction regulation (Avendaño et al. 2017).

Table 2 Effect of miR-505-3p deficiency on female fertility.

\begin{tabular}{|c|c|c|}
\hline Strains & Litters & Dystocia in female (\%) \\
\hline WT & 30 & 0 \\
\hline miR-505-3p +/- & 35 & 31.4 \\
\hline
\end{tabular}

\begin{tabular}{c}
\hline Mean litter size $^{\mathbf{a}}$ \\
\hline $6.032(0.3485)$ \\
$7.125(0.3677)$ \\
\hline
\end{tabular}

\begin{tabular}{c}
\hline P value $^{\mathbf{b}}$ \\
\hline 0.0373 \\
\hline
\end{tabular}

\begin{tabular}{c} 
Dead offspring $(\%$ at $48 \mathrm{~h})$ \\
\hline 1.07 \\
29.8
\end{tabular}

aValues are the mean (S.E.M.). ${ }^{b} P$ value for mean litter size compared to wild type. 

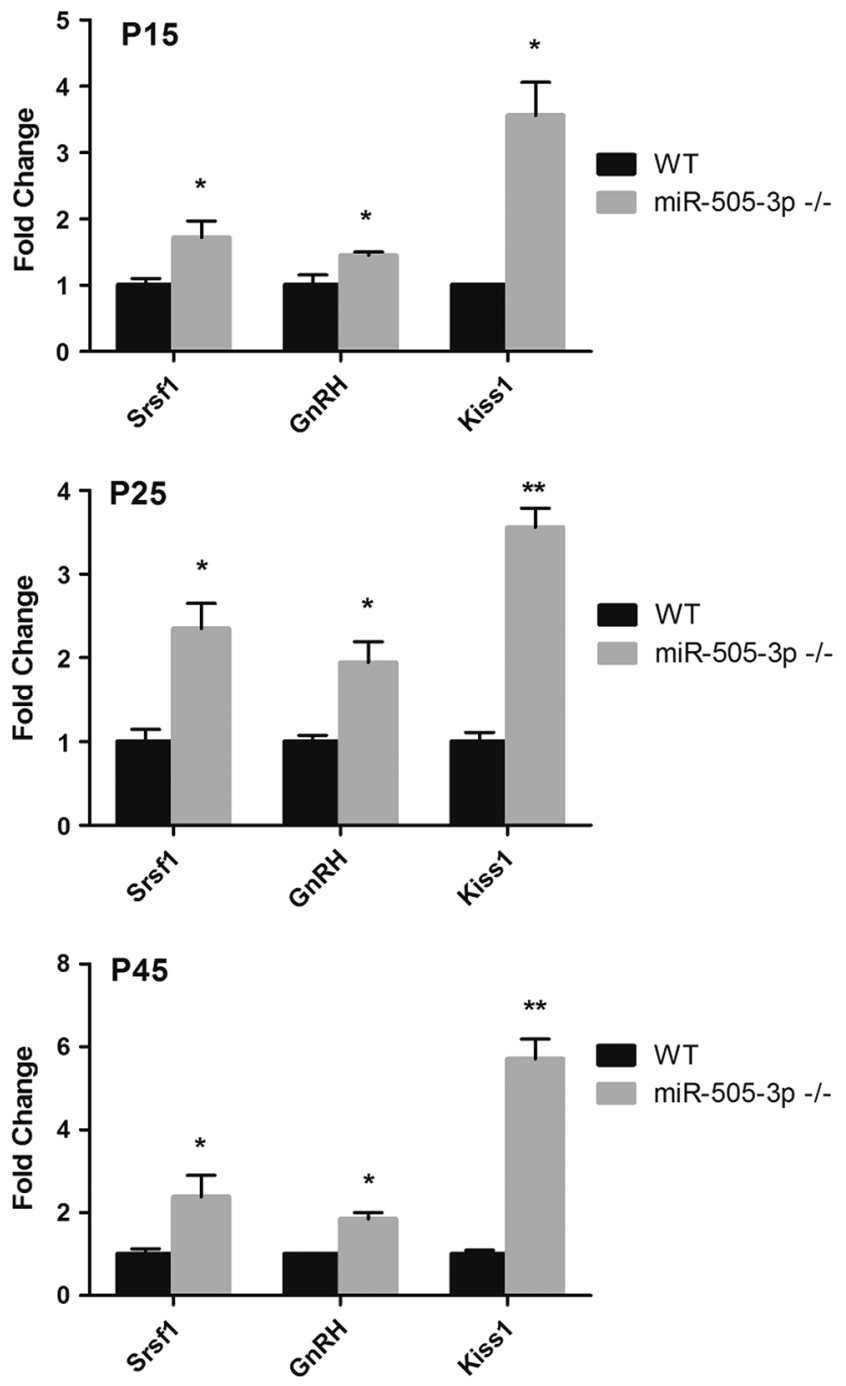

Figure 6

The expression level of Srsf1, Kiss1 and GnRH in the hypothalamus of mir-505-knockout mice at PND15, PND25 and PND45.

miRNAs can function either in the pituitary (Ahmed et al. 2017) or hypothalamus (GnRH neurons) (Messina et al. 2016) to inhibit the expression of the key genes, including $F s h b$ and $L h b$, or Gnrh1, to cause puberty-onset defects and infertility in mice. These researchers discovered that miR-7a2 and miR-155/miR-200 played an essential role in these processes by destroying the expression of these microRNAs in the corresponding tissues. Our results show that overexpression of miR-505-3p in the hypothalamus could cause the delay of puberty and reduced fertility in female mice, and the results from miR-505-3p-knockout mice support this deduction. However, the influence of miR-505-3p on the mouse puberty and fertility was not as intensive as the microRNAs mentioned above,
A

\section{B-tubulin \\ Srsf1}
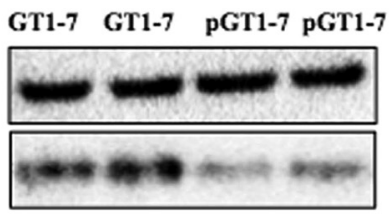

$\begin{array}{llll}1 & 1.08 & 0.59 & 0.61\end{array}$

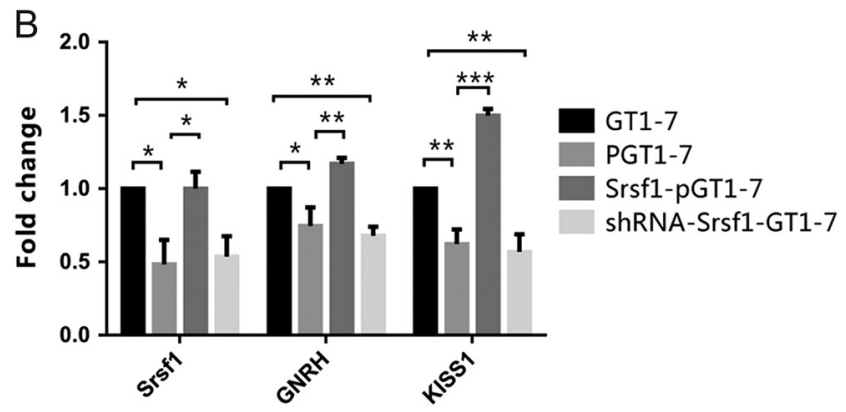

Figure 7

The regulatory role of miR-505-3p on Srsf1 gene expression in GT1-7 cells. (A) The translation of SRSF1 was inhibited by miR-505-3p overexpression in pGT1-7 cell line. (B) The mRNA expression level of Gnrh and Kiss1 varied along with the expression of Srsf1 gene in GT1-7 and pGT1-7 cells.

'Srsf1-pGT1-7' column refers to the pGT1-7 cells transfected by a plasmid carrying a Srsf1 expression cassette. 'shRNA-Srsf1-GT1-7' column refers to the GT1-7 cells transfected by shRNA targeting Srsf1 gene. Bars are means and vertical bars represent S.E.M. $(*, P<0.05 ; * *, P<0.01 ; * \star *, P<0.001 ; \mathrm{ns}$, no statistical significance).

which might be due to the relatively low abundance of miR-505-3p in the mouse hypothalamus. Our experiments in the GT1-7 cell line revealed that miR-505-3p could inhibit puberty-related genes, and its target gene $\operatorname{Srsf1}$ was the key component of the regulating process. However, the signaling pathway that SRSF1 participated in to regulate the expression of Kiss1 or Gnrh is still unclear.

Srsf 1 is the archetype member of the SR (serine and arginine-rich protein) family of splicing regulators and has multiple functions in the cell nucleus and cytoplasm. Moreover, Srsf 1 is also a proto-oncogene in cell malignant transformation (Ong et al. 2009). Previous researches have shown that SRSF1 could bind to ribosomal proteins and participate in mRNA stability, transport, intracellular localization and translation (Shao et al. 2012). Ribosomal proteins play independent key roles in the regulation of apoptosis, multidrug resistance and carcinogenesis (Song et al. 2011, Provost et al. 2014). Our RIP results show that SRSF1 preferentially bind to the mRNA of ribosomal proteins, which has not been reported before. The biological significance of this selectivity has not been clarified, though it encourages us to assume that miR-505-3p may affect the independent roles of ribosomal proteins by inhibiting SRSF1 in GT1-7 cells, and the 
Table 3 Top ten enriched genes by SRSF1 pull down by RNA-seq detection.

\begin{tabular}{|c|c|c|c|}
\hline Ranka & Gene & Valueb & Fold changec (SRSF1/lgG) \\
\hline 1 & Eif4a2 & $15,143.60$ & 4.9594 \\
\hline 2 & Rpl19 & 854.94 & 5.6497 \\
\hline 3 & Ppm1h & 580.72 & 2.9438 \\
\hline 4 & Rpl21 & 571.01 & 4.7366 \\
\hline 5 & Rps14 & 512.69 & 4.3983 \\
\hline 6 & Psmd4 & 440.08 & 3.4028 \\
\hline 7 & Rps9 & 384.78 & 3.8331 \\
\hline 8 & Nudc & 334.29 & 5.0492 \\
\hline 9 & Rpl7 & 332.53 & 4.0535 \\
\hline 10 & Rundc3a & 317.44 & 3.7359 \\
\hline
\end{tabular}

\begin{tabular}{rll}
\cline { 1 - 1 } Rank $^{\mathbf{a}}$ & & Gene \\
\cline { 1 - 1 } 1 & & Rpl19 \\
2 & & Rpl7 \\
3 & & Rps9 \\
4 & & Rpl21 \\
5 & & Rps14 \\
6 & & Ccdc124 \\
7 & Dus11 \\
8 & Psmc4 \\
9 & Nudc \\
10 & Timm23 \\
\hline
\end{tabular}

\begin{tabular}{ccc}
\hline \multicolumn{1}{c}{ Value $^{\mathbf{b}}$} & & Fold change $^{\mathbf{c}}$ (SRSF1/total) \\
\cline { 1 - 1 } $14,741.80$ & & 5.1391 \\
6198.61 & & 4.5250 \\
8300.55 & & 4.0617 \\
6480.69 & & 3.6071 \\
7648.64 & & 3.0312 \\
2878.78 & & 5.8550 \\
1316.45 & & 5.1459 \\
3105.27 & 4.8709 \\
5493.75 & 4.8040 \\
1080.61 & & 4.7274 \\
\hline
\end{tabular}

Ribosome protein genes are in bold fonts. aRanking according to the abundance of the gene in the sample. bThe value given by the RNA-seq data after homogenization. CThe natural logarithm of the ratio of the mRNA abundance between the two samples.

output of these series effects is the downregulation of puberty-related genes. The potential relationship between RP and puberty development needs further elucidation.

We also explored the effect of miR-505-3p on growth rate and found that both miR-505-3p overexpressed and knocked out female mice had a significantly different growth curve from their intact counterparts, while no difference in growth rate existed in the male knockout and WT mice. The mechanism underlying this gender distinction remains unclear, though it coincides with our observation in mISCSs mice, in which we identified that the chromosome X QTL region only influenced the puberty-onset phenotype of female mice. The difference of puberty onset timing mentioned above could not be due to the growth rate difference as the body weight at $\mathrm{VO}$ differed significantly between WT, SKO and DKO mice.

We constructed a miR-505-3p ectopic expression female mouse model by lentiviral delivery. Lentiviral vectors are a versatile tool able to transfect post-mitotic neurons and induce substantial, long-term transgene expression (Zeng et al. 2013, Zhao et al. 2015). Besides reverse transcription and real-time PCR, we performed in situ hybridization for miR-505 detection using improved LNA probes with high specificity and sensitivity. The expression pattern of hypothalamic miR-505-3p detected by in situ hybridization can be used to further elucidate the relationship between miR-505-3p function and the location of miR-505-3p in the hypothalamus.

Finding the target gene of miR-505-3p which underlies puberty onset in female mice can help to describe the regulation mechanism of this complex trait. In our previous work, we identified that one of the important functions of miR-505-3p was that it is a crucial regulator of axonal elongation and branching (through modulating autophagy in neurons) (Yang et al. 2017). Atg12 is the key target gene of miR-505-3p in this process, as its protein product ATG12 (autophagy-related 12) is an essential component of the autophagy machinery during the initiation and expansion steps of autophagosome formation. However, we did not find any influence of miR-505-3p overexpression on the amount of ATG12 in GT1-7 cells, either in the mRNA expression profiling data or qRT-PCR detection, which could be due to the different cell types we used. We found that when cultured in serum reduced medium, $S r s f 1$ became more sensitive to miR-505-3p regulation in GT1-7 cells (Yang et al. 2018). SRSF1 is a regulator of the mTOR pathway, which has been reported to participate in VO modulation in rats (Roa et al. 2009). However, in miR-505-3p-overexpressing pGT1-7 cells, the amount of the marker for activated mTOR signaling (phosphorylated S6K) was not affected, which implied that the inhibition of Srsf 1 expression by miR-505-3p did not influence mTOR signaling in GT1-7 cells. The function of miR-505-3p as a puberty regulator in female mice has been revealed by cell and animal models, but the underlying mechanism still requires further research.

\section{Supplementary data}

This is linked to the online version of the paper at https://doi.org/10.1530/ JOE-18-0533.

\section{Declaration of interest}

The authors declare that there is no conflict of interest that could be perceived as prejudicing the impartiality of the research reported.

\section{Funding}

The National Nature Science Foundation of China (Grant no. 31772550), the Open Project Funding of Human Phenome Institute, Fudan University (HUPIKF2018204). 


\section{Acknowledgements}

The authors appreciate Professor Xiaoying Li in Shanghai Clinical Center for Endocrine and Metabolic Diseases, Shanghai Jiaotong University for providing GT1-7 cells. They also thank Yu Li and Li Chen for help doing some experiments, Fuyi Xu for the assistance of data analysis and Xiaoning Li for the assistance of manuscript writing.

\section{References}

Abreu AP, Dauber A, Macedo DB, Noel SD, Brito VN, Gill JC, Cukier P, Thompson IR, Navarro VM, Gagliardi PC, et al. 2013 Central precocious puberty caused by mutations in the imprinted gene MKRN3. New England Journal of Medicine 368 2467-2475. (https://doi. org/10.1056/NEJMoa1302160)

Ahmed K, LaPierre MP, Gasser E, Denzler R, Yang Y, Rulicke T, Kero J, Latreille M \& Stoffel M 2017 Loss of microRNA-7a2 induces hypogonadotropic hypogonadism and infertility. Journal of Clinical Investigation 127 1061-1074. (https://doi.org/10.1172/JCI90031)

Avendaño MS, Vazquez \& Tena-Sempere M 2017 Disentangling puberty: novel neuroendocrine pathways and mechanisms for the control of mammalian puberty. Human Reproduction Update 23 737-763. (https://doi.org/10.1093/humupd/dmx025)

Bartel DP 2004 MicroRNAs: genomics, biogenesis, mechanism, and function. Cell 116 281-297. (https://doi.org/10.1016/S00928674(04)00045-5)

Chang X, Deng Q, Wang S, Xiao J, Li K \& Zhou Y 2015 Construction of a hypothalamic miR-505 overexpression mouse model. Progress in Modern Biomedicine 15 6005-6008.

Day FR, Perry JR \& Ong KK 2015 Genetic regulation of puberty timing in humans. Neuroendocrinology 102 247-255. (https://doi. org/10.1159/000431023)

Day FR, Thompson DJ, Helgason H, Chasman DI, Finucane H, Sulem P, Ruth KS, Whalen S, Sarkar AK, Albrecht E, et al. 2017 Genomic analyses identify hundreds of variants associated with age at menarche and support a role for puberty timing in cancer risk. Nature Genetics 49 834-841. (https://doi.org/10.1038/ng.3841)

Hasuwa H, Ueda J, Ikawa M \& Okabe M 2013 miR-200b and miR-429 function in mouse ovulation and are essential for female fertility. Science 341 71-73. (https://doi.org/10.1126/science.1237999)

He C, Kraft P, Chen C, Buring JE, Paré G, Hankinson SE, Chanock SJ, Ridker PM, Hunter DJ \& Chasman DI 2009 Genome-wide association studies identify loci associated with age at menarche and age at natural menopause. Nature Genetics 41 724. (https://doi.org/10.1038/ ng.385)

Holder MK \& Blaustein JD 2014 Puberty and adolescence as a time of vulnerability to stressors that alter neurobehavioral processes. Frontiers in Neuroendocrinology 35 89-110. (https://doi.org/10.1016/j. yfrne.2013.10.004)

Karni R, Hippo Y, Lowe SW \& Krainer AR 2008 The splicing-factor oncoprotein SF2/ASF activates mTORC1. PNAS 105 15323-15327. (https://doi.org/10.1073/pnas.0801376105)

Khoo SK, Petillo D, Kang UJ, Resau JH, Berryhill B, Linder J, Forsgren L, Neuman LA \& Tan AC 2012 Plasma-based circulating MicroRNA biomarkers for Parkinson's disease. Journal of Parkinson's Disease $\mathbf{2}$ 321-331.

Kuiri-Hänninen T, Sankilampi U \& Dunkel L 2014 Activation of the hypothalamic-pituitary-gonadal axis in infancy: minipuberty. Hormone Research in Paediatrics 82 73-80.

Lomniczi A, Wright H, Castellano JM, Sonmez K \& Ojeda SR 2013 A system biology approach to identify regulatory pathways underlying the neuroendocrine control of female puberty in rats and nonhuman primates. Hormones and Behavior 64 175-186. (https://doi. org/10.1016/j.yhbeh.2012.09.013)
Lomniczi A, Wright H \& Ojeda SR 2015 Epigenetic regulation of female puberty. Frontiers in Neuroendocrinology 36 90-107. (https://doi. org/10.1016/j.yfrne.2014.08.003)

Mellon PL, Windle JJ, Goldsmith PC, Padula CA, Roberts JL \& Weiner RI 1990 Immortalization of hypothalamic GnRH by genetically targeted tumorigenesis. Neuron 5 1-10. (https://doi.org/10.1016/08966273(90)90028-E)

Messina A, Langlet F, Chachlaki K, Roa J, Rasika S, Jouy N, Gallet S, Gaytan F, Parkash J, Tena-Sempere M, et al. 2016 A microRNA switch regulates the rise in hypothalamic GnRH production before puberty. Nature Neuroscience 19 835-844. (https://doi.org/10.1038/nn.4298)

Ninomiya M, Kondo Y, Funayama R, Nagashima T, Kogure T, Kakazu E, Kimura O, Ueno Y, Nakayama K \& Shimosegawa T 2013 Distinct microRNAs expression profile in primary biliary cirrhosis and evaluation of miR 505-3p and miR197-3p as novel biomarkers. PLoS ONE 8 e66086. (https://doi.org/10.1371/journal.pone.0066086)

Ong KK, Elks CE, Li S, Zhao JH, Luan JA, Andersen LB, Bingham SA, Brage S, Smith GD, Ekelund U, et al. 2009 Genetic variation in LIN28B is associated with the timing of puberty. Nature Genetics 41 729-733. (https://doi.org/10.1038/ng.382)

Pekow JR \& Kwon JH 2012 MicroRNAs in inflammatory bowel disease. Inflammatory Bowel Diseases 18 187-193. (https://doi.org/10.1002/ ibd.21691)

Provost E, Bailey JM, Aldrugh S, Liu S, Iacobuzio-Donahue C \& Leach SD 2014 The tumor suppressor rpl36 restrains KRAS(G12V)-induced pancreatic cancer. Zebrafish 11 551-559. (https://doi.org/10.1089/ zeb.2014.1024)

Prevot V 2015 Chapter 30 - Puberty in mice and rats. In Knobil and Neill's Physiology of Reproduction, 4th edn. San Diego, CA, USA: Academic Press.

Roa J, Garcia-Galiano D, Varela L, Sánchez-Garrido MA, Pineda R, Castellano JM, Ruiz-Pino F, Romero M, Aguilar E, López M, et al. 2009 The mammalian target of rapamycin as novel central regulator of puberty onset via modulation of hypothalamic Kiss1 system. Endocrinology 150 5016-5026. (https://doi.org/10.1210/en.20090096)

Sachdeva M \& Mo YY 2010 miR-145-mediated suppression of cell growth, invasion and metastasis. American Journal of Translational Research 2 170-180.

Sanford JR, Coutinho P, Hackett JA, Wang X, Ranahan W \& Caceres JF 2008 Identification of nuclear and cytoplasmic mRNA targets for the shuttling protein SF2/ASF. PLOS ONE 3 e3369. (https://doi. org/10.1371/journal.pone.0003369)

Sangiao-Alvarellos S, Manfredi-Lozano M, Ruiz-Pino F, Navarro VM, Sánchez-Garrido MA, Leon S, Dieguez C, Cordido F, Matagne V, Dissen GA, et al. 2013 Changes in hypothalamic expression of the Lin28/let-7 system and related microRNAs during postnatal maturation and after experimental manipulations of puberty. Endocrinology 154 942-955. (https://doi.org/10.1210/en.2012-2006)

Shao R, Wang X, Weijdegård B, Norström A, Fernandez-Rodriguez J, Brännström M, Billig H 2012 Coordinate regulation of heterogeneous nuclear ribonucleoprotein dynamics by steroid hormones in the human Fallopian tube and endometrium in vivo and in vitro. American Journal of Physiology: Endocrinology and Metabolism 302 E1269-E1282. (https://doi.org/10.1152/ajpendo.00673.2011)

Sisk CL \& Foster DL 2004 The neural basis of puberty and adolescence. Nature Neuroscience 7 1040. (https://doi.org/10.1038/nn1326)

Song MJ, Jung CK, Park CH, Hur W, Choi JE, Bae SH, Choi JY, Choi SW, Han NI \& Yoon SK 2011 RPL36 as a prognostic marker in hepatocellular carcinoma. Pathology International 61 638-644. (https://doi.org/10.1111/j.1440-1827.2011.02716.x)

Topaloglu AK, Reimann F, Guclu M, Yalin AS, Kotan LD, Porter KM, Serin A, Mungan NO, Cook JR, Imamoglu S, et al. 2008 TAC3 and TACR3 mutations in familial hypogonadotropic hypogonadism reveal a key role for Neurokinin B in the central control of reproduction. Nature Genetics $\mathbf{4 1} 354$. 
Uenoyama Y, Tsukamura H \& Maeda K 2014 KNDy neuron as a gatekeeper of puberty onset. Journal of Obstetrics and Gynaecology Research 40 1518-1526. (https://doi.org/10.1111/jog.12398)

Verduci L, Simili M, Rizzo M, Mercatanti A, Evangelista M, Mariani L, Rainaldi G \& Pitto L 2010 MicroRNA (miRNA)-mediated interaction between leukemia/lymphoma-related factor (LRF) and alternative splicing factor/splicing factor 2 (ASF/SF2) affects mouse embryonic fibroblast senescence and apoptosis. Journal of Biological Chemistry 285 39551-39563.

Xu Y, Faulkner LD \& Hill JW 2011 Cross-talk between metabolism and reproduction: the role of POMC and SF1 neurons. Frontiers in Endocrinology 298.

Yamamoto Y, Yoshioka Y, Minoura K, Takahashi RU, Takeshita F, Taya T, Horii R, Fukuoka Y, Kato T, Kosaka N, et al. 2011 An integrative genomic analysis revealed the relevance of microRNA and gene expression for drug-resistance in human breast cancer cells. Molecular Cancer 10 135. (https://doi.org/10.1186/1476-459810-135)

Yang K, Yu B, Cheng C, Cheng T, Yuan B, Li K, Xiao J, Qiu Z \& Zhou Y 2017 Mir505-3p regulates axonal development via inhibiting the autophagy pathway by targeting Atg12. Autophagy 13 1679-1696.
Yang K, Tong L, Li K, Zhou Y \& Xiao J 2018 A SRSF1 self-binding mechanism restrains Mir505-3p from inhibiting proliferation of neural tumor cell lines. Anti-Cancer Drugs 29 40-49.

Zeng L, He X, Wang Y, Tang Y, Zheng C, Cai H, Liu J, Wang Y, Fu Y \& Yang GY 2013 MicroRNA-210 overexpression induces angiogenesis and neurogenesis in the normal adult mouse brain. Gene Therapy 2137.

Zhao W, Dong Y, Wu C, Ma Y, Jin Y \& Ji Y 2015 miR-21 overexpression improves osteoporosis by targeting RECK. Molecular and Cellular Biochemistry 405 125-133.

Zhu W, Fan Z, Zhang C, Guo Z, Zhao Y, Zhou Y, Li K, Xing Z, Chen G, Liang Y, et al. 2008 A dominant X-linked QTL region regulating pubertal timing in mice found by whole genome scanning and modified interval-specific congenic strain analysis. PLOS ONE 3 e3021.

Zhu H, Shah S, Shyh-Chang N, Shinoda G, Einhorn WS, Viswanathan SR, Takeuchi A, Grasemann C, Rinn JL, Lopez MF, et al. 2010 Lin28a transgenic mice manifest size and puberty phenotypes identified in human genetic association studies. Nature Genetics $\mathbf{4 2} 626$.

Zucchi FC, Yao Y, Ward ID, Ilnytskyy Y, Olson DM, Benzies K, Kovalchuk I, Kovalchuk O \& Metz GA 2013 Maternal stress induces epigenetic signatures of psychiatric and neurological diseases in the offspring. PLOS ONE 8 e56967.

Received in final form 13 December 2018

Accepted 17 December 2018

Accepted Preprint published online 17 December 2018
(C) 2019 Society for Endocrinology Published by Bioscientifica Ltd. 